COLLECTIVISM AND PERCEIVED CONGRUENCE WITH PARENTS

Collectivism and Perceived Congruence with Parents as Antecedents to Career

Aspirations: A Social Cognitive Perspective

Submitted on August 2nd, 2016 
COLLECTIVISM AND PERCEIVED CONGRUENCE WITH PARENTS

\title{
Collectivism and Perceived Congruence with Parents as Antecedents to Career
}

\section{Aspirations: A Social Cognitive Perspective}

\begin{abstract}
Cultural orientation and perceived career congruence with parents are potentially important influences on adolescent career development in collectivist contexts, but few studies have integrated these variables in a social cognitive-based model. We surveyed 337 grade 10 students (53\% girls, mean age 15.9 years) from Central Java, Indonesia, and examined a model which consisted of vertical (VC) and horizontal collectivism (HC), perceived congruence with parents, self-efficacy, and career aspirations. After controlling for SES and school achievement, HC was more strongly associated with perceived congruence with parents than VC, and VC and $\mathrm{HC}$ were indirectly associated with aspirations via congruence and self-efficacy. These two patterns of collectivism were directly and indirectly associated with self-efficacy via congruence, and perceived congruence was indirectly associated with aspirations via self-efficacy. This study underlined the effects of VC, HC, and perceived adolescent-parent career congruence on career decision-making self-efficacy and aspirations of adolescents from a collectivistic country.
\end{abstract}

Keywords: collectivism, adolescent-parent career congruence, self-efficacy, career aspirations 
COLLECTIVISM AND PERCEIVED CONGRUENCE WITH PARENTS

\section{Collectivism and Perceived Congruence with Parents as Antecedents to Career}

\section{Aspirations: A Social Cognitive Perspective}

In the career development literature, expressions of an individual's career goals given ideal conditions are called career aspirations (Rojewski, 2005). Career aspirations formulated during adolescence are important to study as these guide adolescents regarding career-related behaviors (Lent, Brown, \& Hackett, 1994) and serve as precursors to adult career attainment and satisfaction (Mello, 2008). Additionally, the career-goal setting, pursuit, and management processes provide young people with opportunities to develop their vocational identity (Erikson, 1968). Examining both individual factors and environmental affordances in the development of career aspirations is essential, as understanding these two interacting influences can best generate information that can be used to assist adolescents to maximize their potential for future careers and inform parents so that they can facilitate career-related goal setting and goal achievement actions in their adolescent children.

There has been little research examining the role of proximal environmental affordances in the relationship between individual factors and career aspirations in young people. Our study, which was informed by the social cognitive career theory perspective (SCCT; Lent et al., 1994; Lent, Brown, Hackett, 2000), investigated the serial relationships between the important person input of individual-level collectivism (vertical and horizontal collectivism), the significant proximal contextual variable of perceived adolescent-parent career congruence, career decision-making self-efficacy, and career aspirations in a group of adolescents from a collectivistic society (i.e., Indonesia). See Figure 1.

\section{$\underline{\text { Insert Figure } 1 \text { about here }}$}

Level of collectivism, perceived career congruence between adolescents and their parents, and self-efficacy beliefs are prominent antecedents to Indonesian adolescents' career aspirations. Regarding collectivism, Indonesian adolescents have grown up in a country 
COLLECTIVISM AND PERCEIVED CONGRUENCE WITH PARENTS

where people rely on close-others and are interdependent with others generally. Indonesia also has a large power distance index, where, for instance, children, as less powerful family and group members, expect and accept the exercise of control from parents and others who have more power (Hofstede \& Hofstede, 2005). We examined both vertical (VC) and horizontal (HC) patterns of collectivism, which refer, respectively, to the individual's level of in-group interdependence while accepting inequality in the in-group, and interdependence while viewing all members as somewhat equal (Triandis \& Gelfand, 1998), because both collectivist cultural values are likely to affect, in the first instance, children's relationship with their parents, and secondly, their career-related behaviors and direction (Fulmer et al., 2010). Perceived congruence with parents about career matters was included as previous studies have shown this to be important in shaping adolescents' career goals, planning, and exploration in a collectivistic culture (Sawitri, Creed, \& Zimmer-Gembeck, 2014; Sawitri, Creed, \& Zimmer-Gembeck, 2015). Finally, career decision-making self-efficacy was added to the model because research also supports self-efficacy as a prominent contributor to the career development process for young people in collectivistic contexts (e.g., Garcia et al., 2012; Sawitri et al., 2014; Sawitri et al., 2015). As we did not include all SCCT variables in the study (e.g., career interests, outcome expectations), ours was a partial test of the socialcognitive relations with career aspirations.

\section{Career Aspirations from a Social Cognitive Career Theory Perspective}

Adolescent career aspirations are affected by many factors, such as individual characteristics, environment (e.g., family, school), and cultural experiences (Li \& Kerpelman, 2007; Schoon \& Parsons, 2002). According to SCCT (Lent et al., 1994; 2000), young people will set higher career aspirations when they feel a sense of competency in their ability to successfully carry out their goal-related tasks, have a positive belief about the consequences of any career-related actions they implement, and develop pertinent career interests. 


\section{COLLECTIVISM AND PERCEIVED CONGRUENCE WITH PARENTS}

However, these social-cognitive factors are thought to be influenced by three sets of variables: proximal (environmental factors that are influential during an active career decision-making phase) and distal influences (environmental variables that shape the individual before an active period of career decision-making; e.g., socio-economic status), person factors (e.g., personality, cultural orientation), and learning experiences.

For young people from collectivistic cultures, career aspirations are greatly influenced by parent and family wishes and expectations (Fouad et al., 2008). Parental variables that function during the adolescents' active stage of career decision-making are likely to have strong effects on their career-related thoughts and actions (Kim \& Seo, 2014). In support of this, Sawitri et al. (2014) found that both parental career expectations and perceived adolescent-parent career congruence were antecedents to career goals and action behaviors in a group of collectivist teenagers. Although studies have demonstrated a robust role for proximal parental contextual variables in the development of career aspirations of adolescents, few studies have integrated person inputs with proximal contextual variables when testing antecedents of career goals/aspirations (see Rogers, Creed, \& Glendon, 2008). Additionally, fewer have examined these relationships in young people in a collectivistic setting (see Sawitri \& Creed, 2015). The level of interdependence that young people have with their primary group is an important person variable in collectivistic cultures. This variable shapes how they perceive influence from others and affects their decision-making and the aspirations they have for later life and career.

\section{Cultural Orientation and Career Development}

The collectivism/individualism ${ }^{1}$ cultural dimension is the most commonly examined dimension, generally, and in relation to vocational behavior, although studies into cultural

\footnotetext{
${ }^{1}$ Individualism, which reflects the other end of the spectrum from collectivism, is defined as an individual orientation toward autonomy and independence, where personal choice, intrinsic motivation, self-esteem, and self-maximization are important values (Hofstede \& Hofstede, 2005; Triandis, 1995).
} 
COLLECTIVISM AND PERCEIVED CONGRUENCE WITH PARENTS

orientation and career development are quite sparse (Hartung, Fouad, Leong, \& Hardin, 2010). Most research has examined collectivism/individualism as an antecedent to careerrelated attitudes and behaviors, and most studies have been conducted in individualistic contexts. For example, Hartung, Speight, and Lewis (1996) tested the relationship between collectivistic/individualistic orientations and occupational planning and work value orientations in majority-culture university students in the USA, and found weak, negative associations between collectivism and need for occupational prestige and significance of the work role. Hartung et al. (2010) demonstrated positive associations in USA college students between collectivism and work values stressing relationship and interdependence, and negative associations with values related to prestige and financial rewards. In a cross-cultural study, Hughes (2011) examined the relationship between collectivism/individualism and career behaviors in students from an individualistic (i.e., Australia) and a collectivistic context (i.e., Thailand). Australian students who viewed themselves as brighter and having positive parent and peer relationships reported more positive attitudes towards career exploration and planning; whereas, these relationships were not found in the Thai sample. However, questions regarding the influence of cultural orientation on career development need further investigation, especially in collectivist settings.

\section{Linking Collectivism to Career Aspirations via Perceived Congruence and Self-Efficacy}

At the psychological level, collectivism reflects an interdependent self-construal, which represents a socially-defined self that has contextual, connected, and relational qualities that are manifested in the tendency to think of oneself in terms of significant others (Markus \& Kitayama, 1991). For example, for young people with high relationalinterdependent self-construal, any conflict between their own career desires and the need to meet parental wishes regarding their career can make them feel anxious and uncertain about their future career. This happens because they feel compelled to ensure family harmony and 
COLLECTIVISM AND PERCEIVED CONGRUENCE WITH PARENTS

contribute to family prosperity. In relation to career-related goal setting, collectivistic individuals are likely to consider their in-group goals because their own goals and in-group goals necessarily overlap (Markus \& Kitayama, 1991; Triandis, 1995). As young people’s career aspirations in this context are more likely to reflect a compromise between parental wishes and the individual's own desires (Leong \& Chou, 1994), the strength of the individual's level of collectivism will affect their career aspirations, and influence how they go about meeting their goals.

The construct of collectivism/individualism can be differentiated into horizontal (emphasizing equality) and vertical dimensions (valuing hierarchy; Triandis \& Gelfand, 1988), with variation across these two domains leading to different consequences, as shown in the general psychology literature. For example, Chen, Meindl, and Hunt (1997) found that in a collectivistic setting (i.e., China), vertical collectivistic individuals showed a preference for choosing a reward system that fostered hierarchy, whereas horizontal collectivistic individuals preferred an egalitarian reward system that emphasized shared responsibility and interpersonal interdependence. In the career literature, both VC and HC were related positively with family influence in individualistic and collectivistic countries (Fouad et al., 2010; Kim, Ahn, \& Fouad, 2014), but there are no career studies linking patterns of collectivism/individualism and family/parental relationships. This is an important gap as parents are a strong influence on the career direction of their children, affecting not only their level of aspiration but their goal striving behaviors.

Both vertical and horizontal collectivistic individuals are likely to consider the expectations of their in-group (e.g., parents) However, vertical collectivistic individuals tend to focus on obeying authority and maintaining their in-group solidarity, even when it requires sacrificing their own personal goals; whereas, horizontal collectivistic individuals are more likely to focus on sociability and interdependence with others within egalitarian relationships 
COLLECTIVISM AND PERCEIVED CONGRUENCE WITH PARENTS

(Torelli \& Shavitt, 2010; Triandis, 1995). Consequently, vertical collectivistic individuals, when formulating career-related goals, would be more likely to be loyal to their parents and family. They should also tend to favor their parents' wishes when there were differences between their own career preferences and parental aspirations for them. Horizontal collectivistic individuals, on the other hand, would be more likely to see their parents as having an equal relationship with them. They would be more likely to choose negotiation and reconciliation when resolving career-related disparities with their parents. Thus, while we expected both HC and VC to be related to perceived congruence with parents regarding career matters, we considered that HC would be more strongly associated.

Previous studies have used SCCT as the theoretical framework to explain the relationships between parental-related, proximal contextual variables and career outcomes (Garcia, Restubog, Toledano, Tolentino, \& Rafferti, 2012; Restubog, Toledano, \& Garcia, 2010; Tang et al., 1999). These studies demonstrated the important role of different types of family/parental variables (i.e., parental involvement and perceived parental support) in promoting adolescent self-efficacy, career choice (goals), and persistence (actions) in participants from collectivistic cultural backgrounds. For example, in their longitudinal study, Restubog et al. (2010) demonstrated that, in addition to the number of career counselling sessions received at baseline, parental support rated at the same time by both students and parents was related indirectly to later career decidedness via self-efficacy. Garcia et al. (2012) showed that when fostering adolescent self-efficacy, the anticipated consequence of parental actions was more likely to be met if there were fewer discrepancies between parents and their adolescent children in construing parents' intended support.

Additionally, Sawitri et al. (2014), also using SCCT, demonstrated that compared to parental career expectations, perceived career congruence with parents was more strongly associated with self-efficacy. Further, self-efficacy carried most of the influence of perceived 
COLLECTIVISM AND PERCEIVED CONGRUENCE WITH PARENTS

parental variables on career aspirations and related actions. Consistent with SCCT (Lent et al., 1994; 2000), the link from self-efficacy to career aspirations also has been demonstrated in other studies (e.g., Rogers et al., 2008). Therefore, we proposed that perceived career congruence with parents would lead adolescents to have greater self-efficacy, and having a higher level of self-efficacy would encourage them to set higher career aspirations.

\section{The Current Study}

Several studies in the career area have investigated the correlates of cultural orientation in young people (e.g., Hartung et al., 2010; Hartung et al., 1996). However, most studies were conducted in an individualistic context and robust conclusions regarding these relationships have not been established. Research on the consequences of both person inputs and proximal contextual variables in the career development of young people using SCCT as a theoretical basis have been rare in both Western (i.e., individualistic; e.g., Rogers et al., 2008; Rogers \& Creed, 2011) and collectivistic cultures (e.g., Garcia et al., 2012; Sawitri \& Creed, 2015). We investigated the relationships between VC, HC, perceived career congruence with parents, self-efficacy, and career aspirations in a sample of adolescents from a collectivistic society using the SCCT perspective (Lent et al., 1994; 2000). We considered VC and HC as person inputs, perceived career congruence with parents as a proximal contextual variable, and career aspirations as career-related goals. Consistent with SCCT, we also assessed career-decision-making self-efficacy. This study contributes to the understanding of the associations between person inputs (VC and $\mathrm{HC}$ ), proximal contextual variables (perceived career congruence with parents), and career goals (career aspirations) in a collectivistic cultural setting. We expected: (a) both VC and HC to be associated with adolescent-parent career congruence, but HC to be more strongly associated; (b) HC and VC to be associated with career aspirations via perceived congruence and self-efficacy; (c) 
COLLECTIVISM AND PERCEIVED CONGRUENCE WITH PARENTS

perceived congruence to be associated with aspirations via self-efficacy; and (d) HC and VC to be associated with self-efficacy via perceived congruence, as depicted in Figure 1.

We tested our hypotheses on a sample of Grade 10 Indonesian high school students. These students were focused on career development as they had to choose their school major at the end of the Grade 10 year and engage with studies for their major during Grades 11 and 12. The Grade 10 year is their active period of career decision making, as this is when they talk with their parents, peers, and teachers about potential majors and related educational paths in order to achieve their career dreams. Literature on adolescent career development in collectivistic and individualistic contexts has shown that high school years are when students are actively contemplating educational options and a career path. Examining students in Grade 10 provided evidence of the roles of contributing person and contextual variables on their career attitudes (Rogers et al., 2008; Rogers \& Creed, 2011; Sawitri et al., 2015).

\section{Method}

\section{Participants}

Participants were 337 grade 10 Indonesian students (52.5\% girls, mean age $=15.94$ years; $S D=.49)$ from one high school in Central Java, Indonesia. Three students $(0.9 \%)$ indicated "well above average" on a self-report of their common achievement at school, 180 (53.4\%) indicated “above average”, 148 (43.9\%) “average”, and three (1.8\%), reported “low achievement”. Most students (296; 87.8\%) indicated intention to choose one of the natural science streams for their last two years of high school, 38 (11.3\%) had selected social sciences, and three (.9\%) a specialty in languages. As a proxy for SES, we had students report their perceived financial situation: 11 students (3.3\%) reported that their financial situation was “much better” than their peers, 86 (25.5\%) indicated “a little better”, 217 (64.4\%) “about the same”, 20 (5.9\%) “a little worse”, and 3 (.9\%) "much worse”. The majority of the 
COLLECTIVISM AND PERCEIVED CONGRUENCE WITH PARENTS

students (299; 88.7\%) reported no current or previous paid part-time work while studying, which is typical for Indonesia.

\section{Materials}

Unless otherwise indicated, participants responded to all items using a 6-point Likertlike scale (1= strongly disagree to 6 = strongly agree), with higher scores reflecting higher levels of each construct.

Collectivism. The 4-item Vertical Collectivism (VC) and 4-item Horizontal Collectivism (HC) Scales (Triandis \& Gelfand, 1998) were used to assess participants’ levels of vertical and horizontal collectivism. The VC scale measures the degree to which participants emphasize the integrity of the in-group and show a willingness to sacrifice their personal goals for the sake of in-group goals (e.g., "It is my duty to take care of my family, even when I have to sacrifice what I want”). The HC scale assesses the extent to which participants feel connected to others of an equal social level (e.g., "I feel good when I cooperate with others”). The HC and VC validity were supported by using factor analysis with Korean students showing that scores on the two scales were independent, that they were positively related to other collectivism scales, and that they related to other constructs as expected (e.g., related negatively to competition, positively to family integrity, and negatively to emotional distance from in-group; Triandis \& Gelfand, 1998). Internal reliabilities for the scores of the two scales have ranged from .72 to .80 (VC) and .62 to .80 (HC) across different cultural groups in the USA (Torelli \& Shavitt, 2010).

Perceived Career Congruence with Parents. The 12-item Adolescent-Parent Career Congruence Scale (Sawitri, Creed, \& Zimmer-Gembeck, 2013) was used to assess the extent to which participants held similar career values, interests, preferences, and goals as their parents (e.g., "My parents and I have the same way of defining career success”). Alpha of .87 has been reported, and evidence for validity of the scale scores was shown by positive 
COLLECTIVISM AND PERCEIVED CONGRUENCE WITH PARENTS

correlations with living-up-to parental expectations, life satisfaction, parental support in an Indonesian high school sample (Sawitri et al., 2013).

Career Decision-Making Self-Efficacy. We used the 12-item Career Decision Making Self-Efficacy Subscale from the Middle School Self-Efficacy Scale (Fouad, Smith, \& Enoch, 1997) to assess participants' levels of confidence in carrying out career-related tasks. Participants responded to items such as, "How confident are you that you can find information in the library about occupations you are interested in?” on a 6-point scale $(1=$ not confident at all and 6 = highly confident). Higher scores indicate greater self-efficacy beliefs. Internal reliability coefficients of .89 and .79 have been reported with Australian and U.S students, respectively, and construct validity of the scale scores was supported by finding positive associations with other career scales e.g., career outcome expectations, goals, and action behaviors (Creed et al., 2011; Fouad et al., 1997).

Career Aspirations. We used the 10-item Career Aspirations Scale (O'Brien, 1996) to assess participants’ aspirations to become a leader when they enter the workforce (e.g., "When I am established in my working life, I would like to manage other workers”). Alphas of .74 and .72-.77 have been reported and evidence for validity of the scale scores was demonstrated by finding expected correlations with goal orientation, measures of attitude toward women's roles, career-related self-efficacy, and instrumentality in multiple samples of high school and college students of different cultural background (O’Brien, 1996; Gray \& O’Brien, 2007).

\section{Translation}

All of the measures were translated from English to Bahasa using the standard five-step translation-back-translation procedure (Brislin, 1986): (a) two bilingual speakers translated the items into Bahasa; (b) two monolingual speakers checked the readability of the translated version; (c) two bilingual speakers who were unfamiliar with the original version back- 


\section{COLLECTIVISM AND PERCEIVED CONGRUENCE WITH PARENTS}

translated the items into English; (d) the back-translation was compared with the original to check the semantic equivalence and precision, and errors were then corrected; and (e) three Indonesian Grade 10 students evaluated the final readability of the survey package.

\section{Procedure}

We obtained approvals from the authors' university, the city education department, the participating school, and the students' parents, and the students signed their own consent forms. The first author and research assistants administered the survey package containing the above scales in class time. Participation in the study was voluntary, and those who did not take part were set an alternative activity arranged by the teacher. The survey booklets were returned to the researchers in a sealed envelope. We distributed 389 packages and had 337 usable questionnaires returned, giving a response rate of $87 \%$. Surveys that were deemed unusable were those where students had patterned responses (e.g., all responses ticked as “1”), failed to correctly respond to multiple check questions, had substantial missing data, were not completed at all, or were not finished.

\section{Statistical Analyses}

The hypothesized structural model was examined using latent variable analysis (maximum likelihood estimation using AMOS V21). We represented the five latent variables using a combination of observed items and multi-item parcels to meet recommended ratios of sample size to parameters estimated (20:1; Kline, 2011). HC and VC were each represented by four individual observed items, whereas perceived congruence, self-efficacy, and career aspirations were each represented by three multi-item parcels (Hau \& Marsh, 2004; Landis, Beal, \& Tesluck, 2000). The parcels were formed by subjecting the items of each scale to separate exploratory factor analyses, ranking the items by factor loading, and then allocating a mixture of high and low items to each parcel. Parcels were created by using the sum of the items allocated to them (Little, Cunningham, Shahar, \& Widaman, 2002). 


\section{COLLECTIVISM AND PERCEIVED CONGRUENCE WITH PARENTS}

We first examined a measurement model to ensure that the five latent variables were adequately represented by their parcels and items, and then tested the hypothesized structural model depicted in Figure 1 . We used $\chi^{2}$, the normed $\chi^{2}\left(\chi^{2} / \mathrm{df}\right)$, the Comparative Fit Index (CFI), and the Root Mean Square Error of Approximation (RMSEA) as indices of fit for the models. Hair, Black, Babin, and Anderson (2010) specified that with a sample of 337 and 14 observed variables, an acceptable fit was indicated by a significant $\chi^{2}, \chi^{2} / \mathrm{df}<3.0$, CFI $>.92$, and RMSEA $<.07$.

\section{Results}

The measurement model, $\chi^{2}(109)=205.57, p<.001, \chi^{2} / \mathrm{df}=1.89$, CFI $=.95$, RMSEA $=.05$ showed good fit statistics, with factor loadings ranging from .41 to $.89(p<.001)$. Table 1 reports summary data, zero-order correlations, correlations among the latent variables, and internal reliability coefficients.

\section{Insert Table 1 about here}

Socio-economic status (SES) and school achievement had significant bivariate correlations with perceived congruence ( $r=.13, r=.11, p<.05$, respectively) and career aspirations ( $r=.14, p<.05 ; r=.15, p<.01)$, and SES had significant correlations with selfefficacy $(r=.17, p<.01)$. Therefore, we tested the hypothesized structural model (Figure 1 ), while including SES and school achievement as covariates.

We found good fit statistics for the hypothesized structural model, $\chi^{2}(154)=271.87, p$ $<.001, \chi^{2} / \mathrm{df}=1.77, \mathrm{CFI}=.94, \mathrm{RMSEA}=.05$. All paths were significant: vertical collectivism $\rightarrow$ congruence $(\beta=.19, p<.01)$, horizontal collectivism $\rightarrow$ congruence $(\beta=.33$ $p<.001)$, congruence $\rightarrow$ self-efficacy $(\beta=.65 p<.001)$, self-efficacy $\rightarrow$ aspirations $(\beta=.57$, $p<.001)$, SES $\rightarrow$ self-efficacy $(\beta=.12, p<.05)$, and school achievement $\rightarrow$ aspirations $(\beta=$ $.13, p<.05)$. In sum, $19 \%$ of the variance in congruence, $44.1 \%$ in self-efficacy, and $34.4 \%$ in aspirations were accounted for (Figure 2). 
COLLECTIVISM AND PERCEIVED CONGRUENCE WITH PARENTS

We tested the mediation paths by assessing a structural model that contained the direct effects only, examining a model that contained both the direct and indirect effects, and estimating standard errors and 95\% bias-corrected confidence intervals using the AMOS bootstrapping technique (Shrout \& Bolger, 2002). First, we tested if there were indirect paths from horizontal and vertical collectivism to aspirations (via congruence and self-efficacy). We confirmed that the direct effects for HC and VC to aspirations were both significant (both $\beta=.17, p<.05)$. We then examined the direct and indirect effects together using 1,000 bootstrapped samples, and found significant paths from VC $(\beta=.21, p<.01)$ and $\mathrm{HC}(\beta=$ $.25, p<.001) \rightarrow$ congruence, congruence $\rightarrow$ self-efficacy $(\beta=.65, p<.001)$, and selfefficacy $\rightarrow$ aspirations $(\beta=.56, p<.001)$, indicating all requirements for mediation were met. HC $(\beta=.04, p=.56)$ and VC $(\beta=.01, p=.85)$ were not significantly associated with aspirations in the presence of the mediators, and the indirect CIs did not include zero (CIs = .02 to .15 and .04 to .16). Thus, we concluded that congruence and self-efficacy fully mediated the effects of HC and VC on career aspirations.

Using the same procedure, we tested if there were indirect effects from HC and VC to self-efficacy via congruence, and if there was an indirect effect from congruence to aspirations via self-efficacy. We concluded that congruence partially mediated between VC and HC and self-efficacy; and self-efficacy fully mediated between congruence and aspirations. Paths between VC $(\beta=.17, p<.05)$ and HC $(\beta=.25, p<.001)$ and self-efficacy remained significant in the presence of the mediator of perceived congruence, and were included in Figure 2.

\section{Insert Figure 2 about here}

\section{Discussion}

This study tested the serial relationships between horizontal and vertical collectivism, perceived career congruence between adolescents and their parents, career decision-making 
COLLECTIVISM AND PERCEIVED CONGRUENCE WITH PARENTS

self-efficacy, and career aspirations. We assessed a sample of adolescents from a collectivistic context and used the SCCT framework (Lent et al., 1994; 2000). Findings of this study expand the range of correlates of adolescent career decision-making self-efficacy and aspirations in collectivistic cultures (e.g., Garcia et al., 2012; Sawitri \& Creed, 2015). The current study also extends on the few previous SCCT-based studies that have examined the roles of person inputs and proximal contextual variables on the career development of adolescents and young adults in Western (i.e., individualistic; e.g., Rogers \& Creed, 2011; Rogers et al., 2008) and collectivistic settings (e.g., Garcia et al., 2012; Sawitri \& Creed, 2015). It also expands our knowledge related to the career-related consequences of cultural orientations, which mostly have been examined in the individualistic contexts (e.g., Hartung et al., 2010; Hartung et al., 1996).

First, confirming H1, we found that compared to VC, HC was more strongly correlated with perceived career congruence with parents. This indicates that young people with a higher orientation to relate to others at a similar level are more likely to have higher levels of perceived congruence with their parents regarding career issues than those who are oriented to accept inequality and view the self as differing from others along a hierarchy. Viewing parents as partners in their career development process, adolescents who value equality might feel little or no pressure for being different from their parents (Otto, 2000). Therefore, they might achieve congruence more easily by communicating their own career preferences with their parents. As the development of a unique, independent self is restricted when hierarchy is valued (Kurman \& Sriram, 2002), those who value inequality might try to conform with their parents by giving up or compromising on their own career goals in favor of their parents' wishes. This could be reflected in them thinking that they have limited opportunity to share their career ideas because they are more likely to see parents as someone 
COLLECTIVISM AND PERCEIVED CONGRUENCE WITH PARENTS

to look up to, and to see themselves as having an obligation to "live-up to” their parents’ expectations and wishes.

Further, we found that VC and HC were associated positively with career aspirations via perceived career congruence and self-efficacy, supporting H2. In the first instance, this suggests that those who have a higher focus on dutifully fulfilling obligations to others (i.e., vertical collectivists) and on sociability and treating others with selflessness (i.e., horizontal collectivists) are more likely to develop career congruence with their parents. This happens because their patterns of collectivism lead them to be more attuned to the needs and wishes of their significant others (i.e., parents; Markus \& Kitayama, 1991). Subsequently, having a greater degree of congruence helps these adolescents to develop a higher level of confidence in their ability to successfully carry out career-related tasks. Finally, this increased confidence leads them to set higher career aspirations. This result is consistent with Hardin, Leong, and Osipow (2001) who argued that interdependent (collectivistic) individuals are more likely to consider the preferences of significant others in addition to their own when making careerrelated decision, and that they are also more likely to be confident when perceiving themselves to be supported by their parents (cf. Oettingen \& Zosuls, 2006).

Partly supporting H3, we found that both $\mathrm{HC}$ and VC were associated positively with self-efficacy, directly, and indirectly via perceived congruence. This suggests that not only does perceiving a stronger connection with parents and family lead to higher confidence in carrying out career-related tasks by improving perceived career congruence with their parents, but being vertically and horizontally collectivistic also directly encourages these adolescents to be more efficacious. This is in line with Triandis et al.'s (1988) argument that compared to individualistic people, collectivistic individuals have greater needs for nurturance, affiliation, and support from their in-group, and demonstrate a higher level of willingness to give help and support to in-group members as they feel that they are part of the 
COLLECTIVISM AND PERCEIVED CONGRUENCE WITH PARENTS

in-group. Therefore, being congruent with parents regarding career matters is in line with cultural expectations and the individual's sense of self (Hardin et al., 2001), which is beneficial for their career confidence and capacity to deal with career-related issues (Garcia et al., 2012; Leung, Hou, Gati, \& Li, 2011).

HC was more strongly associated with self-efficacy than VC. As VC is positively associated with conformity and HC is more associated with benevolence (Soh \& Leong, 2002), seeing parents as partners in the career development process is more likely to increase these adolescents' career confidence, rather than having to focus on complying with parental authority. The relationship between VC and being more reserved also explains this finding: adolescents who have higher levels of VC are more likely to be retiring (Kurman \& Sriram, 2002), and thus tend to develop lower self-efficacy.

Finally, consistent with H4, we found that self-efficacy carried the effect of perceived congruence to career aspirations. This finding indicates that being congruent with parents regarding career matters is likely to develop adolescents’ confidence in conducting careerrelated activities. In turn, this will lead them to set higher career aspirations. This is consistent with Leong and Chou's (1994) findings that for an individual from a collectivist cultural background, a career is an indicator of a compromise between parental expectations and individual preferences.

This study is one of the few to date to investigate the association between cultural orientation and career development in young people. The study demonstrated that adolescents in a collectivistic setting will aspire to higher career goals when they have both higher HC and VC orientations, perceive a higher degree of congruence with their parents regarding career matters, and have higher levels of career efficacy beliefs. However, having higher levels of HC is more beneficial because compared to VC, HC makes it easier for them to achieve perceived career congruence with their parents and to build higher levels of efficacy 
COLLECTIVISM AND PERCEIVED CONGRUENCE WITH PARENTS

beliefs. Adolescents with this pattern of collectivism are more likely to see their parents as equal partners, therefore, a higher level of HC opens up more opportunities for them to communicate their career preferences and identity to their parents, and negotiate with parents when there are different opinions regarding career-related ideas.

The findings suggest that career counsellors need to explore adolescent levels and patterns of collectivism and levels of perceived career congruence with their parents when helping them develop confidence in performing career tasks. These areas need to be probed when assisting them to formulate career goals, as this will lead to different strategies to achieve congruence. Our findings also suggest that those working with adolescents should help them identify and be aware of their levels of HC and VC, and to master relevant strategies to develop congruence with parents regarding career matters based on their types of collectivism.

Additionally, the results suggest that parents should: (a) be aware that their children's patterns and levels of collectivism affect their children's perceived career congruence with them, and affect their children's self-efficacy and career aspirations; (b) be ready to resolve any differences between their career wishes for their children and their children's own preferences that might occur based on their children's type of collectivism, as this will have an effect on their children's career development; (c) be willing to be allies to their children and to foster this way of relating, as this is more likely to increase their children's levels of congruence and foster their career development; and (d) be prepared not to use their power to push children to merely follow the parents' wishes. In sum, parents should develop resources to help their children set and achieve their career dreams based on their children's own capabilities and preferences in the context of their own in-group/family wishes.

The differential consequences of HC and VC on perceived career congruence with parents and self-efficacy should encourage future researchers to examine the two patterns of 
COLLECTIVISM AND PERCEIVED CONGRUENCE WITH PARENTS

collectivism in relation to other career outcomes, such as the extent to which adolescents plan and explore their future career. In order to confirm the role of $\mathrm{HC}$ and VC in the career development of adolescents in collectivistic contexts, future studies should compare collectivist societies with different levels of HC and VC. HC and VC and their relationship with career-related outcomes also need to be examined in individualist contexts to obtain cross-cultural applicability.

Our study was based on the well-supported SCCT model, containing two patterns of collectivism, perceived congruence, self-efficacy, and career aspirations in a sample of adolescents from a collectivistic country. However, this study is not without its limitations. First, readers should carefully interpret the findings of this study as both vertical and horizontal collectivism scale scores had internal consistency levels marginally below 0.70 . This is not uncommon in scales with a small number of items (Nunnally \& Bernstein, 1994), but future research should seek to employ scales that can be expected to perform above this level. We were not able to assess the cross-cultural measurement invariance of the two scales used in our study to determine if item content was being perceived and interpreted appropriately by our sample (Byrne \& Watkins, 2003), and this could be tested in future studies. Second, our participants were drawn from one high school using a convenience sampling technique. As this might reduce the external validity of the findings in this cultural context, there is a need to be careful when generalizing the results to other groups of young people in other collectivistic countries. Third, we only included the collectivism cultural construct in the study; thus, future research needs to explore the associations between other aspects of cultural orientation (e.g., vertical and horizontal individualism) and career outcomes. Finally, the cross-sectional nature of our data did not allow us to confirm the serial relationships proposed, nor to test for reverse and reciprocal effects between person inputs, proximal resources, and career goals. For example, individuals with a higher level of 
COLLECTIVISM AND PERCEIVED CONGRUENCE WITH PARENTS

confidence in carrying out career tasks might have a larger capacity to compile available environmental resources. Thus, they might also be more likely to view those contextual affordances in a more positive way (Lent et al., 2000). As only a few studies have examined the longitudinal nature of person inputs, proximal resources, and career goals (e.g., Rogers \& Creed, 2011), there is a need to investigate the across-time relationships between these variables to draw more robust causal conclusions in both collectivistic and individualistic contexts. 
COLLECTIVISM AND PERCEIVED CONGRUENCE WITH PARENTS

References

Brislin, R. W. (1986). The wording and translation of research instruments. In W. J. Lonner \& J. W. Berry (Eds.). Field methods in cross-cultural research (pp. 137-164). London, UK: Sage Publications, Inc.

Byrne, B. M., \& Watkins, D. (2003). The issue of measurement invariance revisited. Journal of Cross-Cultural Psychology, 34, 155-175. doi:10.1177/0022022102250225

Chen, C. C., Meindl, J. R., \& Hunt, R. G. (1997). Testing the effects of vertical and horizontal collectivism: A study of reward allocation preferences in China. Journal of Cross-Cultural Psychology, 28, 44-70. doi:10.1177/0022022197281003

Creed, P., Tilbury, C., Buys, N., \& Crawford, M. (2011). The career aspirations and action behaviors of Australian adolescents in out-of-home-care. Children and Youth Services Review, 33, 1720-1729. doi:10.1016/j.childyouth.2011.04.033

Erikson, E. H. (1968). Identity: Youth and crisis. New York, NY: Norton.

Fouad, N. A., Cotter, E. W., Fitzpatrick, M. E., Kantamneni, N., Carter, L., \& Bernfeld, S. (2010). Development and validation of the Family Influence Scale. Journal of Career Assessment, 18, 276-291. doi:10.1177/1069072710364793

Fouad, N. A., Kantamneni, N., Smothers, M. K., Chen, Y.-L., Fitzpatrick, M., \& Terry, S. (2008). Asian American career development: A qualitative analysis. Journal of Vocational Behavior, 72, 43-59. doi:10.1016/j.jvb.2007.10.002

Fouad, N. A., Smith, P. L., \& Enochs, L. (1997). Reliability and validity evidence for the Middle School Self-Efficacy Scale. Measurement and Evaluation in Counseling and Development, 30, 17-31. Retrieved from http://mec.sagepub.com/

Fulmer, C. A., Gelfand, M. J., Kruglanski, A. W., Kim-Prieto, C., Diener, E., Pierro, A., \& Higgins, E. T. (2010). On "feeling right” in cultural contexts: How person-culture 
COLLECTIVISM AND PERCEIVED CONGRUENCE WITH PARENTS

match affects self-esteem and well-being. Psychological Science, 21, 1563-1569. doi:10.1177/0956797610384742

Garcia, P. R., Restubog, S. R., Toledano, L. S., Tolentino, L. R., \& Rafferti, A. L. (2012). Differential moderating effects of student- and parent-rated support in the relationship between learning goal orientation and career decision-making self-efficacy. Journal of Career Assessment, 29, 22-33. doi:10.1177/1069072711417162

Gray, M. P., \& O’Brien, K. M. (2007). Advancing the assessment of women’s career choices: The Career Aspirations Scale. Journal of Career Assessment, 15, 317-337. doi: 10.1177/1069072707301211.

Hair, J. F., Black, W. C., Babin, B. J., \& Anderson, R. E. (2010). Multivariate data analysis. A global perspective. (7th ed.). New Jersey, NJ: Prentice Hall.

Hardin, E. E., Leong, F. T. L., \& Osipow, S. H. (2001). Cultural relativity in the conceptualization of career maturity. Journal of Vocational Behavior, 58, 36-52. doi:10.1006/jvbe.2000.1762

Hartung, P. J., Fouad, N. A., Leong, F. T., \& Hardin, E. E. (2010). Individualism collectivism links to occupational plans and work values. Journal of Career Assessment, 18, 34-45. doi:10.1177/1069072709340526

Hartung, P. J., Speight, J. D., \& Lewis, D. M. (1996). Individualism-collectivism and the vocational behavior of majority culture college students. The Career Development Quarterly, 45, 87-96. doi:10.1002/j.2161-0045.1996.tb00464.x

Hau, K.-T., \& Marsh, H. W. (2004). The use of item parcels in structural equation modelling: Non-normal data and small sample sizes. British Journal of Mathematical and Statistical Psychology, 57, 327-351. doi:10.1111/j.2044-8317.2004.tb00142.x Hofstede, G., \& Hofstede, G. J. (2005). Cultures and organizations: Software of the mind (2nd ed.). New York, NY: McGraw-Hill. 


\section{COLLECTIVISM AND PERCEIVED CONGRUENCE WITH PARENTS}

Hughes, C. (2011). The influence of self-concept, parenting style, and individualismcollectivism on career maturity in Australia and Thailand. International Journal for Educational and Vocational Guidance, 11, 197-210. doi:10.1007/s10775-011-9208-1

Kim, S., Ahn, T., \& Fouad, N. (2014). Family influence on Korean students’ career decisions: A social cognitive perspective. Journal of Career Assessment, 18, 1-14. doi:10.1177/1069072715599403

Kim, M. S., \& Seo, Y. S. (2014). Social cognitive predictors of academic interest and goals in South Korean engineering students. Journal of Career Development, 41, 526-546. doi: $10.1177 / 0894845313519703$

Kline, R. B. (2011). Principles and practice of structural equation modeling. (3 ${ }^{\text {rd }}$ ed.). New York, NY: The Guildford Press.

Kurman, J., \& Sriram, N. (2002). Interrelationships among vertical and horizontal collectivism, modesty, and self-enhancement. Journal of Cross-Cultural Psychology, 33, 71-86. doi:10.1177/0022022102033001005

Landis, R. S., Beal, D. J., \& Tesluk, P. E. (2000). A comparison of approaches to forming composite measures in structural equation models. Organizational Research Methods, 3, 186-207. doi:10.1177/109442810032003

Lent, R. W., Brown, S. D., \& Hackett, G. (1994). Toward a unifying social cognitive theory of career and academic interest, choice, and performance. Journal of Vocational Behavior, 45, 79-122. doi:10.1006/jvbe.1994.1027

Lent, R. W., Brown, S. D., \& Hackett, G. (2000). Contextual supports and barriers to career choice: A social cognitive analysis. Journal of Counseling Psychology, 47, 36-49. doi:10.1037//0022-0167.47.1.36 
COLLECTIVISM AND PERCEIVED CONGRUENCE WITH PARENTS

Leong, F, T, L., \& Chou, E. L. (1994). The role of ethnic identity and acculturation in the vocational behavior of Asian Americans: An integrative review. Journal of Vocational Behavior, 44, 155-172. doi:10.1006/jvbe.1994.1011

Leung, S. A., Hou, Z.-J., Gati, I., \& Li, X. (2011). Effects of parental expectations and cultural-values orientation on career decision-making difficulties of Chinese university students. Journal of Vocational Behavior, 78, 11-20. doi:10.1016/j.jvb.2010.08.004

Li, C., \& Kerpelman, J. (2007). Parental influences on young women’s certainty about their career aspirations. Sex Roles, 56, 105-115. doi:10.1007/s11199-006-9151-7

Little, T. D., Cunningham, W. A., Shahar, G., \& Widaman, K. F. (2002). To parcel or not to parcel: Exploring the question, weighing the merits. Structural Equation Modeling: A Multidisciplinary Journal, 9, 151-173. doi:10.1207/s15328007sem0902_1

Markus, H, R., \& Kitayama, S. (1991). Culture and the self: Implications for cognition, emotion, and motivation. Psychological Review, 98, 224-253. doi:10.1037/0033295X.98.2.224

Mello, Z. R. (2008). Gender variation in developmental trajectories of educational and occupational expectations and attainment from adolescence to adulthood. Developmental Psychology, 44, 1069-1080. doi:10.1037/0012-1649.44.4.1069

Nunnally, J, \& Bernstein, I. (1994). Psychometric theory (3rd ed.). New York, NY: McGrawHill.

O'Brien, K. M. (1996). The influence of psychological separation and parental attachment on the career development of adolescent women. Journal of Vocational Behavior, 48, 257-274. doi:10.1006/jvbe.1996.0024 
COLLECTIVISM AND PERCEIVED CONGRUENCE WITH PARENTS

Oettingen, G., \& Zosuls, K.M. (2006). Culture and self-efficacy in adolescents. In F. Pajares \& T. Urdan. (Eds.), Self-efficacy beliefs of adolescents. Volume V of adolescence and education (pp. 245-265). Greenwich, CT: Information Age Publishing.

Otto, L. B. (2000). Youth perspectives on parental career influence. Journal of Career Development, 27, 111-118. doi:10.1023/A:1007848600942

Restubog, S. L. D., Florentino, A. R., \& Garcia, P. R. J. M. (2010). The mediating roles of career self-efficacy and career decidedness in the relationship between contextual support and persistence. Journal of Vocational Behavior, 77, 186-195. doi:10.1016/j.jvb.2010.06.005

Rogers, M. E., \& Creed, P. A. (2011). A longitudinal examination of adolescent career planning and exploration using a social cognitive career theory framework. Journal of Adolescence, 34, 163-172. doi:10.1016/j.adolescence.2009.12.010

Rogers, M. E., Creed, P. A., \& Glendon, A. I. (2008). The role of personality in adolescent career planning and exploration: A social cognitive perspective. Journal of Vocational Behavior, 73, 132-142. doi:10.1016/j.jvb.2008.02.002

Rojewski, J. W. (2005). Career aspirations. In S. D. Brown \& R. W. Lent (Eds.), Career development and counseling. Putting theory and research to work. (pp. 131-154). New Jersey, NJ: John Wiley \& Sons.

Sawitri, D. R., \& Creed, P. A. (2015). Perceived career congruence between adolescents and their parents as a moderator between goal orientation and career aspirations. Personality and Individual Differences, 81, 29-34. doi:10.1016/j.paid.2014.12.061

Sawitri, D. R., Creed, P. A., \& Zimmer-Gembeck, M. J. (2015). Longitudinal relations of parental influences and adolescent career aspirations and actions in a collectivist society. Journal of Research on Adolescence, 25, 551-563. doi:10.1111/jora.12145 
COLLECTIVISM AND PERCEIVED CONGRUENCE WITH PARENTS

Sawitri, D. R., Creed, P. A., \& Zimmer-Gembeck, M. J. (2014). Parental influences and adolescent career behaviours in a collectivist cultural setting. International Journal for Educational and Vocational Guidance, 14, 161-180. doi:10.007/s10775-013-9247$\mathrm{x}$

Sawitri, D. R., Creed, P. A., \& Zimmer-Gembeck. (2013). The Adolescent-Parent Career Congruence Scale: Development and initial validation. Journal of Career Assessment, 21, 210-226. doi:10.1177/1069072712466723

Schoon, I., \& Parsons, S. (2002). Teenage aspirations for future careers and occupational outcomes. Journal of Vocational Behavior, 60, 262-288. doi:10.1006/jvbe.2001.1867

Shrout, P. E., \& Bolger, N. (2002). Mediation in experimental and nonexperimental studies: New procedures and recommendations. Psychological Methods, 7, 442-445. doi:10.1006/jvbe.2001.1867

Soh, S., \& Leong, F. T. (2002). Validity of vertical and horizontal individualism and collectivism in Singapore. Relationships with values and interests. Journal of CrossCultural Psychology, 33, 3-15. doi:10.1177/0022022102033001001

Tang, M., Fouad, N. A., \& Smith, P. L. (1999). Asian Americans' career choices: A path model to examine factors influencing their career choices. Journal of Vocational Behavior, 54, 142-157. doi:10.1006/jvbe.1998.1651

Torelli, C. J., \& Shavitt, S. (2010). Culture and concepts of power. Journal of Personality and Social Psychology, 99, 703-723. doi:10.1037/a0019973

Triandis, H. C., \& Gelfand, M. J. (1998). Converging measurement of horizontal and vertical individualism and collectivism. Journal of Personality and Social Psychology, 74, 118-128. doi:10.1037/0022-3514.74.1.118 
COLLECTIVISM AND PERCEIVED CONGRUENCE WITH PARENTS

Triandis, H. C., Bontempo, R., Villareal, M. J., Assai, M., \& Lucca, N. (1988). Individualism and collectivism: Cross-cultural perspectives on self-ingroup relationships. Journal of Personality and Social Psychology, 54, 323-338. doi:10.1037/0022-3514.54.2.323

Triandis, H. C. (1995). Individualism and collectivism. Boulder, CO: Westview. 


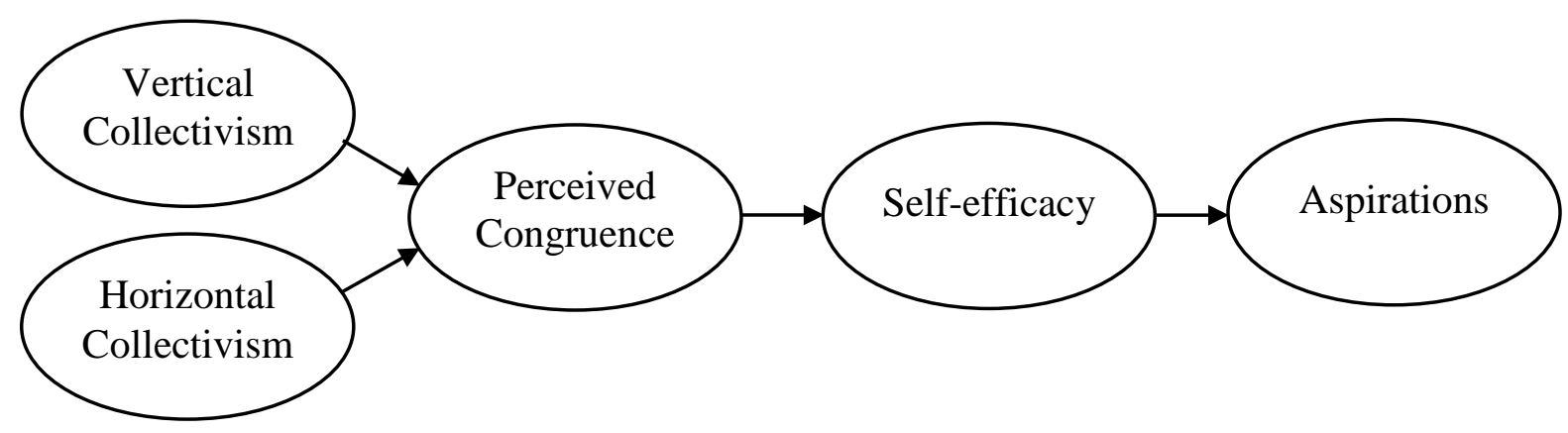

Figure 1. Hypothesized structural model, with horizontal and vertical collectivism indirectly associated with aspirations via perceived congruence and self-efficacy 


\section{COLLECTIVISM AND PERCEIVED CONGRUENCE WITH PARENTS}

Table 1

Inter-correlations, Means, Standard Deviations, and Cronbach Alphas; $N=337$

\begin{tabular}{lcccccccc}
\hline \multicolumn{1}{c}{ Variables } & 1 & 2 & 3 & 4 & 5 & $M$ & SD & $\alpha$ \\
\hline 1. Horizontal collectivism & - & $.35^{* *}$ & $.25^{* *}$ & $.35^{* *}$ & $.17^{* *}$ & 19.07 & 2.16 & .65 \\
2. Vertical collectivism & $.40^{* * *}$ & - & $.26^{* *}$ & $.31^{* *}$ & $.15^{* *}$ & 18.76 & 2.77 & .68 \\
3. Perceived congruence & $.37^{* * *}$ & $.28^{* * *}$ & - & $.51^{* *}$ & $.33^{* *}$ & 53.35 & 8.33 & .89 \\
4. Self-efficacy & $.49^{* * *}$ & $.40^{* * *}$ & $.63^{* * *}$ & - & $.39 * *$ & 54.80 & 6.20 & .79 \\
5. Career aspirations & $.27^{* *}$ & $.23^{* *}$ & $.44^{* * *}$ & $.56^{* * *}$ & - & 46.53 & 8.04 & .72
\end{tabular}

Note. Correlations among scales above diagonal; correlations among latent variables below. ${ }^{* *} p<.01, * * * p<.001$ 


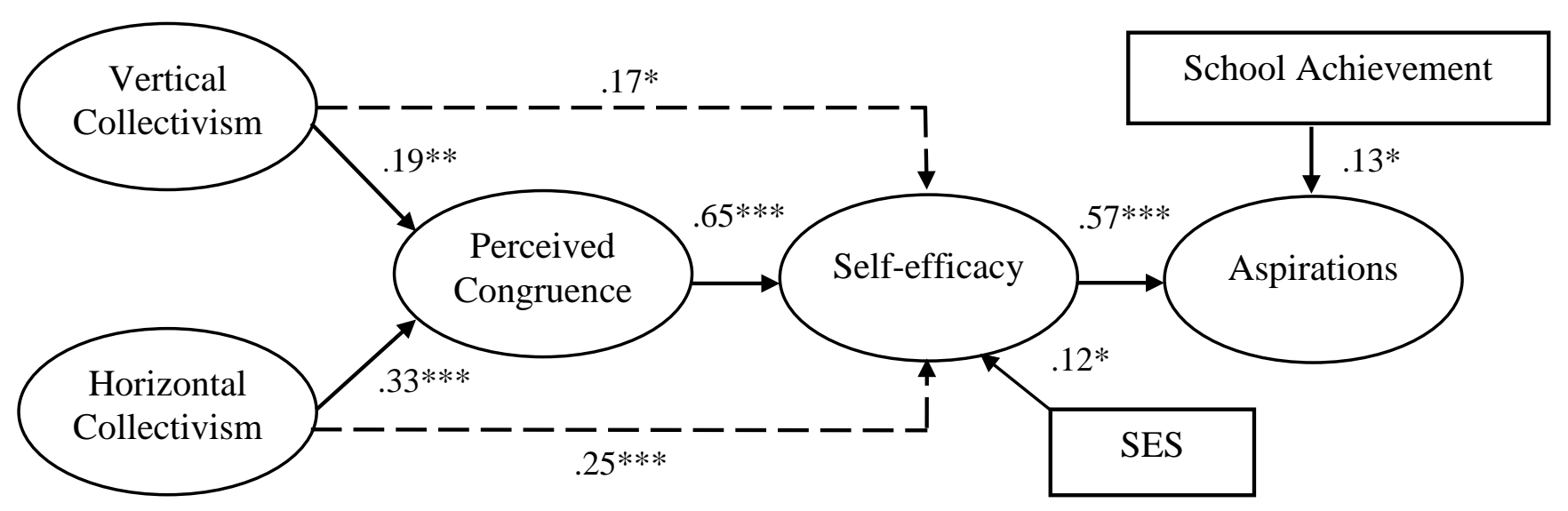

Figure 2. Pathways in structural model are represented by full lines; direct effects revealed in the mediation testing are represented by dashed lines. ${ }^{*} p<.05$, ** $p<.01$, *** $p<.001$ 